\title{
Colorectal Cancer from Molecular Pathways to Gene Therapy
}

\author{
Christoforos Kosmidis ${ }^{1}$, Paul Zarogoulidis ${ }^{2}{ }^{\bowtie}$, George Efthimidis ${ }^{1}$, Sofia Baka ${ }^{3}$, Christoforos Efthimiadis ${ }^{1}$, \\ Ioannis Tzitzikas', Nikolaos Michalopoulos 5 , Konstantinos Sapalidis ${ }^{5}$, Yan-Gao Man ${ }^{6}$, Isaak Kesisoglou ${ }^{5}$ \\ 1. Surgery Department, Interbalkan European Medical Center, Thessaloniki, Greece; \\ 2. Pulmonary Deparment-Oncology Unit, Drug Design and Development Laboratory, "G. Papanikolaou” General Hospital, Aristotle \\ University of Thessaloniki, Thessaloniki, Greece; \\ 3. Oncology Department, Interbalkan European Medical Center, Thessaloniki, Greece; \\ 4. Radiotherapy Department, "AHEPA" University General Hospital, Aristotle University of Thessaloniki, Thessaloniki, Greece; \\ 5. Third Surgery Department, "AHEPA" University General Hospital, Aristotle University of Thessaloniki, Thessaloniki, Greece. \\ 6. Laboratory of Proteomics and Protein Sciences, Veterans Affair Health System, Baltimore, MD, USA.
}

$\square$ Corresponding author: Paul Zarogoulidis, M.D, Ph. D, Pulmonary Department-Oncology Unit, “G. Papanikolaou” General Hospital, Aristotle University of Thessaloniki, Thessaloniki, Greece Fax: 00302310992424 Mobile: 00306977271974 E-mail: pzarog@hotmail.com

(c) Ivyspring International Publisher. This is an open access article distributed under the terms of the Creative Commons Attribution (CC BY-NC) license (https://creativecommons.org/licenses/by-nc/4.0/). See http://ivyspring.com/terms for full terms and conditions.

Received: 2017.01.12; Accepted: 2017.02.27; Published: 2017.05.06

\begin{abstract}
Nowadays colorectal cancer is still considered the third most common cancer in the world. The tumorigenesis mechanisms of colorectal cancer have been widely studied at a molecular level. It has been observed that morbidity and mortality caused by colorectal cancer impacts on the global economy. This occurs through the loss of productivity and the burden on the healthcare system. Therefore an effort is made by several researchers to expend considerably their resources to develop treatments and preventative strategies to reduce the incidence of colorectal cancer. A Large-scale sequencing of genome, proteome, microbiome, and transcriptome analyses of colorectal cancer tissue has allowed researchers to better understand colorectal cancer subtypes. Until now the following parameters have been identified with the etiology of colorectal cancer genetic mutations, inflammatory processes, diet, and the gut microbes. In the current review we will present the molecular pathways of CRC and discuss novel gene therapy approaches.
\end{abstract}

Key words: gene therapy, molecular pathways, colorectal cancer.

\section{Introduction}

According to the latest statistical studies colorectal cancer $(\mathrm{CRC})$ is considered the third most common cancer occurring worldwide [1]. Although several efforts have been made towards diagnosis and treatment, unfortunately; the incidence and mortality of colorectal cancer is still high. It has been observed that the incidence of CRC has increased in most countries in the past decade, due to the changes in lifestyle and everyday diet [2]. It has been observed that physical activity is a key factor that may significantly reduce the risk of colon cancer and can be easily be adopted in the everyday lifestyle. In a recently published meta-analysis in 2009 [3] both men and women benefited from the protective effect of exercise. In this study the protective effect in men seemed a bit more pronounced than in women $(24 \%$ versus $21 \%$ ) when the two genders were compared. It was also observed in this study that physical activity also reduced the risk of rectal cancer, but the effect was not as strong as that in colon cancer [4, 5]. Moreover; reduced incidence of colon cancer was observed in professionals that required continuous daily physical activity. In recently published studies it was observed that nearly $20 \%$ of patients were 
diagnosed at an advanced stage with metastatic disease. The survival rate of CRC was detected at a localized stage is $90.3 \%$. [6-8] It is known that approximately half of the CRC diagnosed patients will eventually progress with metastasis. Liver is known to be the most common metastatic site. Other organs which also CRC metastasize are the lung and bone. $[9,10]$ There are several examinations such as; blood testing, immunochemical/molecular testing, and colonoscopy-based screening which are used for screening in developed countries as a preventive measure for the detection of CRC in its early stages. Colorectal cancer diagnosed in early stage is known that $10 \%$ to $30 \%$ still relapses with metastases within two years of surgical treatment.[11, 12] Researchers in order to address this issue they use various technologies such as aCGH, metaphase, and next-generation sequencing. This technology can identify prognostic biomarkers in early stage CRC. Array-based analysis of DNA copy number aberrations (CNAs), it has been observed to be very effective in identifying recurrent CNAs in CRC. Moreover; it has been argued that CNAs of recurrent nature may be involved in their evolutionary importance in driving CRC progression.[13, 14] Furthermore; early detection of cancer will reduce the number of cancer death because development of a colorectal carcinoma may take several years. We need early detection, so there is a large window of opportunity for curable disease. Moreover; current studies have identified that ineffective therapies are due to lack of our understanding of precise molecular mechanism involved in carcinogenesis. Finally, chemotherapy is often associated with severe adverse reactions.[15-17] Currently, different multidrug combinations that combine agents with proven anticancer activity, such as 5-fluorouracil, capecitabine, oxaliplatin and irinotecan, have been used for colorectal cancer therapy in the clinic.[18-20] These drug combinations are being used after patient molecular screening in order to identify the best combination. Hence, novel approaches for treatment of colorectal cancer are needed.

\section{Search Methods}

We performed an electronic article search through PubMed, Google Scholar, Medscape and Scopus databases, using combinations of the following keywords: colorectal cancer molecular pathways, gene therapy. All types of articles (randomised controlled trials, clinical observational cohort studies, review articles, case reports) were included. Selected references from identified articles were searched for further consideration.

\section{Molecular Pathways}

Nowadays it is known that for the epigenetic alteration, the most studied mechanisms are DNA methylation, modifications in histone proteins, and microRNAs [21-23]. In specific the Mutations of TSGs APC (Wnt pathway controlling gene) and TP53 (genome integrity pathway controlling gene) and oncogene KRAS (mitogen-activated protein kinases [MAPK]-signaling pathway controlling gene) are known to be critical [24] in colon cancer development and progression. It has been observed that, the KRAS gene is mutated in $30 \%-50 \%$ of colon cancer tumors $[25,26]$. Moreover; chemotherapy with oxaliplatin is suggested that is correlated the activity MAPK, JAK-STAT, and PI(3)K-AKT-mTOR pathways, which belong to the EGFR-signaling network.[27]Moreover; concurrent mutations such as APC and KRAS are high in tumor cells of colon cancer.[24] Furthermore; mutations of other genes including PIK3CA, SMAD4, and TP53 are known to trigger the tumor malignancy and induce metastasis [24]. In mutated KRAS gene several variants in codons G12 (27\%) and G13 (9.1\%) have been observed [28]. In specific, the variants G12D, G12V, and G13D at exons 2 are among the most common mutations of KRAS gene,[29] representing $12 \%, 7.3 \%$, and $8.1 \%$ colon cancer cases, respectively.[28] Moreover; there are four mutated genes (AXIN1, KRAS, MLH1, and TGFBRII), which are associated with the activity of the drugs and belong to distinct pathways. The molecular regulation of KRAS and MTOR genes, which belong to MAPK and PI(3)K-AKT-mTOR pathways respectively, correlate with the activity of both oxaliplatin and 5-FU. In laboratory findings it was observed that the activation of the PI(3)K-AKT-mTOR pathway resulted in drug resistance to oxaliplatin [30] and 5-FU51-53 in colon cancer cell lines. Several variants of some genes were investigated and it was observed that they were related to the EGFR-signaling network and correlated with the activity of oxaliplatin or 5-FU or both in the colon cancer cell lines. It is speculated based on these findings that members of the EGFR-signaling network may be used as potential targets alone or together with oxaliplatin and 5-FU for colon cancer treatment [31]. Moreover; it has been observed that aberrant Wnt signaling pathway is associated with a wide array of tumor types and this pathway plays an important role in the maintenance of stemness of colorectal stem cells $[32,33]$.

Over the past decade research has shown that cells harboring loss-of-function mutation involving components of the Wnt signaling cascade, such as APC, $\beta$-catenin and Axin. [34-36] cause aberrant 
transcriptional induction of $\mathrm{Wnt} / \beta$-catenin target genes.[37, 38] Novel drug was presented in a recent study indicating that XAV939 a novel small molecule inhibitor of WNT signaling pathway, can brake Wnt signaling pathway in cancer cell lines through binding to tankyrase (TNKS) catalytic poly-ADP-ribose polymerase (PARP) domain. The inhibition results in a marked stabilization of the Axin protein, finally leading to increased $\beta$-catenin destruction.[39] XAV939 resulted in the WNT pathway inhibition and induced apoptosis by 5-FU/DDP, accompanied by lowering the protein expression level alteration of $\beta$-catenin, Axin and CSC markers in colon cancer cells.[40] There are several genes such as; IGF1, ESR1, MMP1, and F2, that are known to be colon adenocarcinoma-related genes. Insulin-like growth factor-1 (IGF-1) is known to be one of the factors contributing to the increased risk in colon cancer.[30] Insulin-like growth factor-1 can activate also, many more signaling pathways involved in carcinogenesis, such as; PI3K/Akt, MAPK, and STAT3.[41] Therefore; inhibition of these pathways may have preventive and therapeutic potential. Estrogen receptor-alpha (ESR1) is also known to be increased in colon cancer cell proliferation and also, increases cancer incidence.
During investigation of colorectal adenocarcinoma cancer cell lines it was observed that NR3C1and PGR genes were not annotated to be colon adenocarcinoma-related, they were associated, however; they were associated with other cancers. However; evidence shows that NR3C1 displayed methylation in carcinomas and that it could appear occasionally in the early events in colorectal cancer development.[42] Previous studies indicated that there is a significant impact of progesterone receptors (PGR) on prognosis of ER+/HER2- breast cancer.[43] Moreover; PGR positivity is correlated with response to tamoxifen therapy, both in the adjuvant setting and metastatic setting.

Furthermore, the PGR status is an independent predictive factor for survival.[44] It is speculated that PGR and NR3C1 genes may also have significant relationship with colon adenocarcinoma. MiR-590 has been also investigated and it was found to be a complement region of RhoB gene.[45] RhoB is known to have tumor suppressor activity. MiRNAs have been found to play important roles in regulating hub nodes and could serve as biomarkers to identify colon adenocarcinoma.[45,46] (Figures 1 and 2)

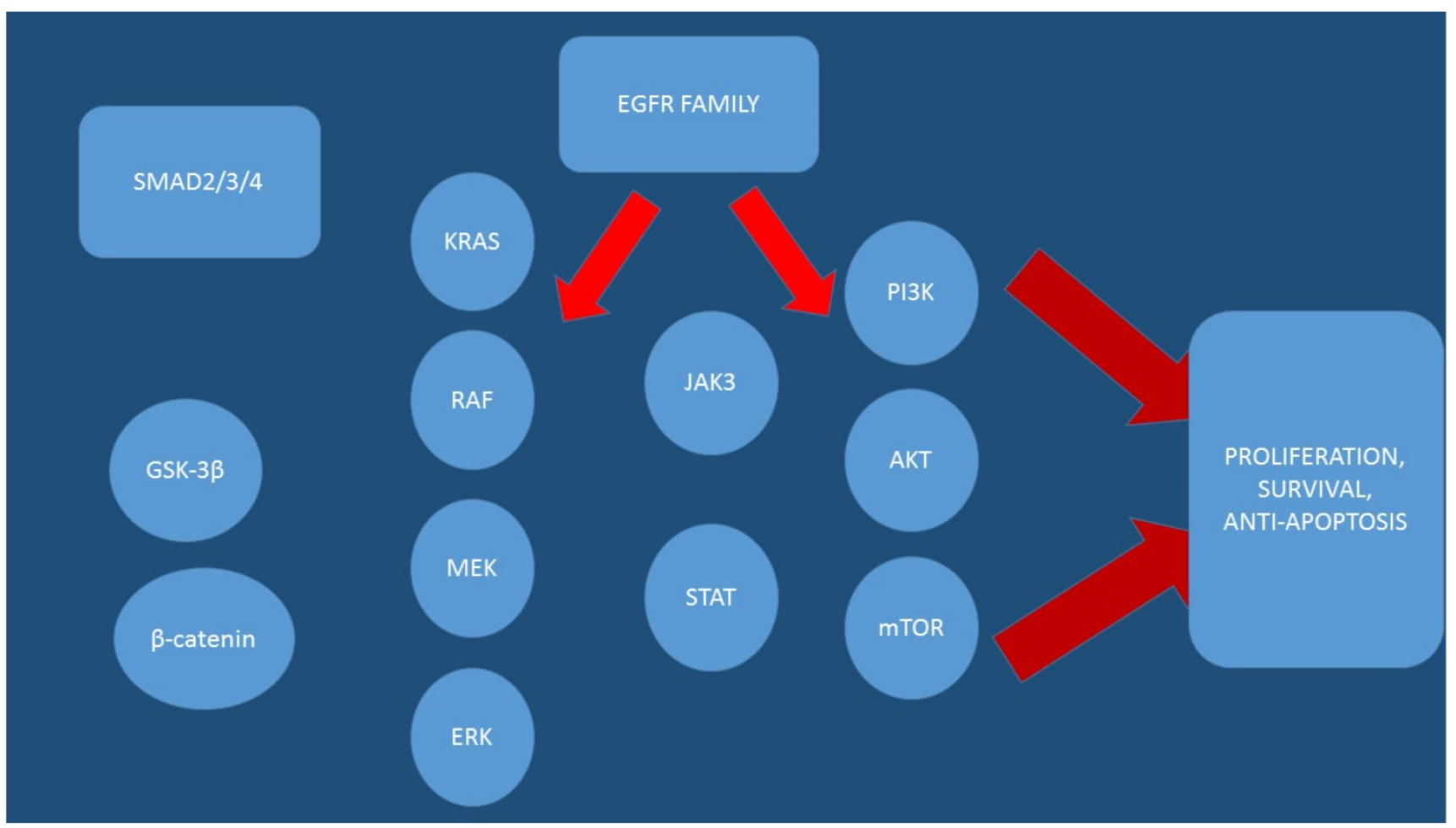

Figure 1. EGFR; epidermal growth factor, AKT; Protein kinase B (PKB), mTOR; mammalian target of rapamycin, MEK; Mitogen-activated protein kinase kinase (also known as MAP2K, MEK, MAPKK), ERK; Extracellular signal-regulated kinases STAT; signal transducer and activator of transcription (STAT) protein family, JAK3; Tyrosine-protein kinase JAK3, SMAD2/3/4; SMADs are intracellular proteins that transduce extracellular signals from transforming growth factor beta ligands, PI3K; Phosphatidylinositol-4,5-bisphosphate 3-kinase (also called phosphatidylinositide 3-kinases, phosphatidylinositol-3-kinases, $\mathrm{PI}$ 3-kinases, PI(3)Ks, RAF; RAF kinases are a family of three serine/threonine-specific protein kinases that are related to retroviral oncogenes, KRAS; $\mathrm{V}$-Ki-ras2 Kirsten rat sarcoma viral oncogene homolog 


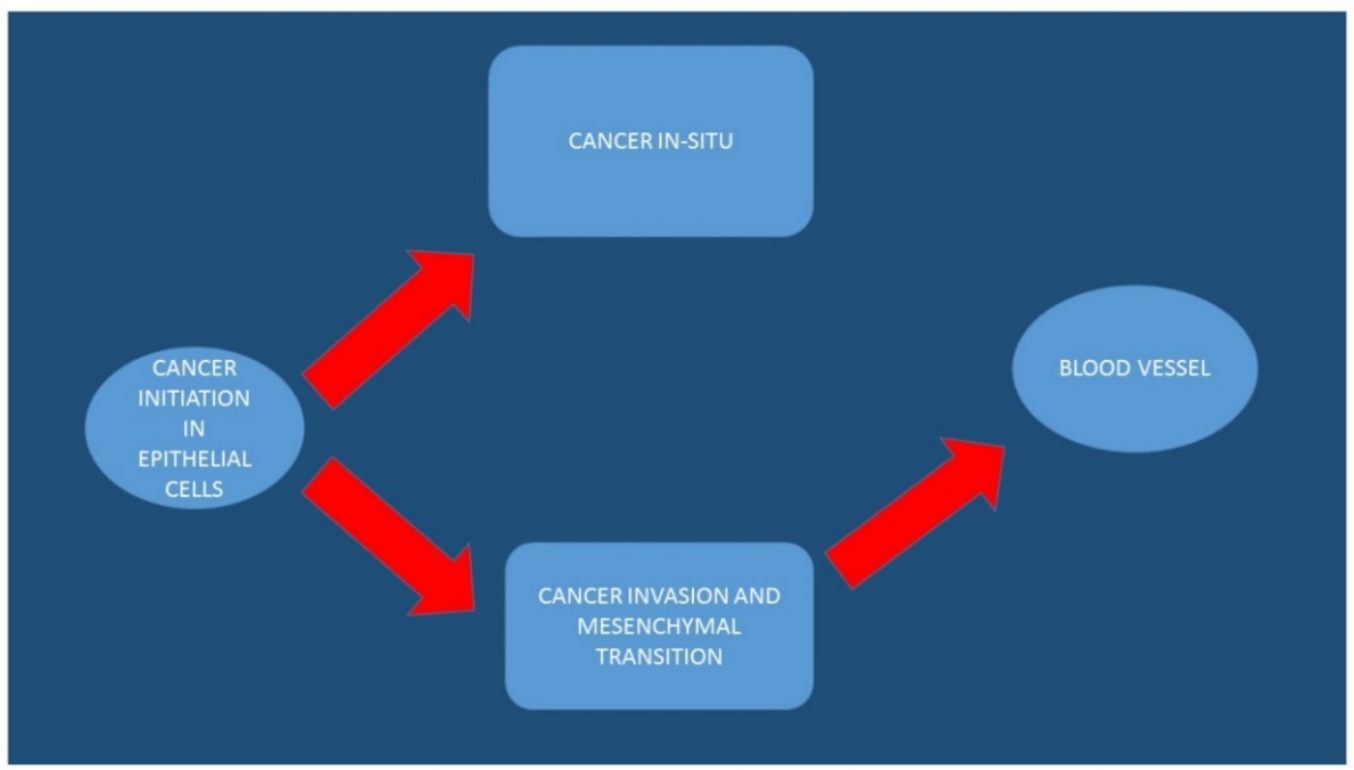

Figure 2. The arrows indicate the initiation, transition and progression of colorectal cancer cells

\section{Gene Therapy}

Nowadays gene therapy is proposed as a novel treatment $\mathrm{CRC}$, in specific preclinical data using adenovirus vectors have shown promising results and a number of clinical trials utilizing this vector are underway.[47, 48] Previously the safety of adenovirus vectors has been established in various phase I trials, however, the factors determining the efficiency of gene delivery still remain under investigation. To enhance the efficiency of in vivo siRNA delivery, delivery systems, including viral and non-viral vectors, have been developed. Viral vectors can achieve highly efficient gene transfer but have the risk of causing undesired immune stimulation.[49] In contrast, non-viral vectors such as cationic polymeror micelle based carriers ("polyplexes" or "micelleplexes")[50] and liposomes have been reported as good siRNA carriers that can suppress expression of target genes with very little immunotoxicity.[51] And polymers such as polyethylene glycol (PEG) can be conjugated to siRNA to further improve its stability and prolong its blood circulation time after intravenous (i.v) administration. [52] In the study by Lee S. Y. et. al. [53] a multifunctional theranostic micellar drug delivery system utilizing cationic PDMA-block-poly( $\varepsilon$ caprolactone) (PDMA-b-PCL) micelles as nanocarriers of SN-38 (7-ethyl-10- hydroxycamptothecin) was developed. Additionally, the SN-38/USPIO-loaded siRNA-PEG mixed micelleplexes acted as a negative magnetic resonance imaging (MRI) contrast agent in T2-weighted imaging, resulting in a powerful tool for the diagnosis and for tracking of the therapeutic outcomes.

In summary, we established a theranostic micellar drug and gene delivery system that not only synergistically combined gene silencing and chemotherapy but also served as a negative MRI contrast agent, which reveal its potential as a novel colorectal cancer therapy. The utilization of biocompatible nanocarriers allows integration of multiple functions, including drug loading, tumor-specific targeting delivery, and gene delivery. In the study by Hussain A. et. al. [54] it was observed that PI3K pathway signaling up-regulated cancer cell proliferation, metastasis and angiogenesis through modulation of cancer metabolism. These oncogenic metabolic processes were disrupted, by a novel PI3K inhibitor, 3-Dihydro-2-(naphthalene-1-yl) quinazolin$4(1 \mathrm{H})$ - one (DHNQ) in colon cancer cells. DHNQ inhibited the Warburg effect and lipid synthesis by reducing gene expression of glycolytic and lipogenesis regulatory enzymes. In the study by Davudian S. et. al. [55] results indicated that BACH1 down-regulation in HT29 CRC cells had no effect on cell growth, however; they inhibited cell migration by decreasing metastasis-related gene expression. These results suggested that BACH1 may function as an oncogenic driver in colon cancer and may represent a potential target for gene therapy for colorectal cancer treatment.

In the study by Kiani M. et. al. [56] Polyelectrolyte complex (PEC) nanoparticles (PECs) of chitosan and thiolated dextran were used as either an injectable or oral gene delivery system. hSET1 
antisense was loaded into the polyelectrolyte complex (PEC) nanoparticles (PECs) to suppress proliferation of colon cancer cell line. The nanoparticles prepared had $\sim 115 \mathrm{~nm}$ diameter size and positive zeta potential with high mucoadhesion properties. They were able to protect antisense from degradation in serum and biorelevant fluids (FaSSIF and FaSSGF). The prepared nanoparticles demonstrated superior cellular penetration and inhibitory effect on SW480 colon cancer cell proliferation. It was observed that all nanoparticles significantly down regulated hSET1 in comparison to naked antisense. It can be concluded that thiolated polyelectrolyte complex (PEC) nanoparticles (PECs) have potential use for injectable or oral delivery of nucleic acids such as antisense. In the study by Liang X. et. al. [57] F-PLP/pIL15, a FRa-targeted lipoplex loading recombinant interleukin-15 plasmid (pIL15) was constructed. Its antitumor effects in vivo using a CT26 colon cancer mouse model was investigated. It was observed that targeted delivery of IL15 gene might be associated with its in vivo antitumor effects, which include inhibiting tumor proliferation, inducing tumor cell apoptosis, and promotion of the activity of immune cells such as $\mathrm{T}$ cells and natural killer cells. Most importantly with the additional help of hematoxylin and eosin staining of vital organs following F-PLP/pIL15 treatment no detectable toxicity was observed. Indicating that intraperitoneal administration of this therapy is safe. F-PLP/pIL15 could be considered a potential targeting preparation for colon cancer therapy.

In the study by Ayeka P.A.et. al. [58] it was observed that G.uralensis polysaccharides especially those of low molecular weight could be used as anticancer agents. Polysaccharides can up-regulate anticancer cytokine IL-7, which is important in proliferation and maturation of immune cells. This compound can be used for immunomodulation in cancer therapy. In the study by Zhang B. et. al. [59] the recombinant L. lactis NZ9000-401-kiss1 successfully expressing the human kiss1 was constructed. It was observed that the secreted KiSS1 peptide inhibited human HT-29 cells' proliferation and migration probably. The mechanism of action was probably induced by invoking, or mediating the cell-apoptosis pathway and by down regulating MMP-9 expression, respectively. Results suggested that $L$. lactis is an ideal cell factory for secretory expression of tumor metastasis-inhibiting peptide KiSS1, and that could serve as a new tool for cancer therapy in the future. In the study by Song L. et. al. [60] the targeted delivery system for $\beta 6$-siRNA was constructed and it was suggested that it could be an approach to improve therapeutic efficacy of colon cancer. In specific integrin $\beta 6$ target immune-liposomes were constructed for high efficiency and selective delivery of $\beta 6$-siRNA in colon cancer, which consequently resulted in greater growth suppression, invasion and metastasis of colon cancer cells.

In the study by Ye P. et. al. [61] it was observed that HDAC2 can regulate Dox sensitivity of CRC cells by targeting $A B C B 1$ transcription. Moreover; it was suggested that HDAC2 might be an important target for colorectal cancer therapy. Furthermore, the combination of HDAC2-specific inhibitor and anticancer drugs including Dox might be an efficiency doublet approach to enhance treatment of colorectal cancer. In the study by Oh Y. B. et al. [62] siRNA-mediated down-regulation of livin gene expression and it was observed that it could significantly suppress colon cancer growth and enhance the cytotoxic effects of the anticancer drugs 5-FU and L-OHP. It was observed that silencing livin gene expression in combination with treatment with anticancer drugs might be a novel dual anti-cancer therapy for CRC. In the study by $\mathrm{Yu}$ T. et. al. [63] a novel gene delivery system based on the newly synthesized copolymer COOH-PEG-PLGA-COOH (CPPC) was developed. In this study this construction was capable of overcoming the disadvantages of viral vectors and cationic lipids/polymers-based non-viral carriers. In this study PEDF gene loaded CPPC nanoparticles (D-NPs) were fabricated by a modified double-emulsion water-in-oil-in-water $(\mathrm{W} / \mathrm{O} / \mathrm{W})$ solvent evaporation method. Increased in vitro antitumor effect was found in two cell lines C26 and A549 cells treated by D-NPs. Furthermore D-NPs were also investigated for their in vivo antitumor activity in a C26 subcutaneous tumor model by intravenous injection and demonstrated that D-NPs could achieve a significant antitumor activity with sharply reduced micro-vessel density and significantly promote tumor cell apoptosis. Moreover; it was observed both in vitro and in vivo serological and biochemical analysis that D-NPs had no obvious toxicity. All data indicated that the novel CPPC nanoparticles are ideal vectors for the systemic delivery of PEDF gene and could be a potential gene delivery system.

In the study by Zhou D. et al. [64] plasmid of small interfering RNA (siRNA) to interfere with GHR expression under diseased conditions involving hepatic metastases in colon cancer was constructed. In the study by $\mathrm{Li} \mathrm{K}$. et al. [65] results indicate that siRNA-mediated silencing of $\beta$-catenin could inhibit the proliferation and invasion of SW480 cells and induce apoptosis. In the study by Zhao C. et. al. [66] a non-peptide small molecule STAT3 inhibitor, LY5, using in silico site-directed Fragment-based drug 
design (FBDD) was constructed. The inhibitory effect on STAT3 phosphorylation, cell viability, migration and colony forming ability by LY5 were examined in human liver and colon cancer cells. It was observed that LY5 inhibited constitutive interleukin-6 (IL-6)-induced STAT3 phosphorylation, STAT3 nuclear translocation, decreased STAT3 downstream targeted gene expression and induced apoptosis in liver and colon cancer cells. Moreover; LY5 had little effect on STAT1 phosphorylation mediated by IFN- $\gamma$.

In the study by Wang Y. et. al. [67] a combination of antitumor effects combining interleukin-2/ interferon- $\beta$-based gene therapy in colorectal cancer was administered. In this study it was observed that transfection of the fusion gene expression plasmid induced significant apoptosis of Lovo cells. Furthermore; the fusion gene exhibited strong inhibitory activity against tumor growth and apoptosis when the complex was injected into the nude mice implanted with human CRCs. Moreover; the tail-vein injection presented a more notable effect than direct injection into tumor. Combined interleukin-2/interferon- $\beta$-based gene therapy with the carcinoembryonic antigen promoter might be an effective novel antitumor strategy. In the study by Zhu P. et. al.[68] a new delivery system, pluronic P85 block copolymers, combining the chemotherapeutic agent 5-fluorouracil (5-Fu) for inhibiting growth and metastasis of colon cancer was designed and developed. In this study, it was demonstrated that 5 -Fu produce a strong pesticide effect at lower doses in the present of pluronic P85 compared to control groups. It was observed that 5-Fu/P85 copolymer micelles could inhibit the growth and metastasis of colon cancer, which could be attributed to the decrease of the content of CD133 + CXCR4+ cells and suppression of EMT of CD133 + CXCR4+ cells. In the study by Zho Y-S. et. al. [69] it was demonstrated that species B-based adenoviral gene therapy could be a suitable approach for generally CD46-overexpressed CRC but would require a careful consideration preceding CD46 analysis and categorizing CRC patients. (Table 1)

Table 1. Gene therapy formulations with eluting drugs

-Magneto-fluorescent silica nanoparticles (MFSN) [70]

- Folic acid conjugated guar gum nanoparticles (MTXFA-GGNP)

- Wheat germ agglutinin (WGA)-functionalised

chitosan-Ca-alginate (CTS-Ca-ALG) microparticles (MPs) [71]

- Anti-VEGF antibodyconjugated dextran-coated iron oxide nanoparticles (anti-EGF-NPs) [72]

- HA modified mesoporous silica nanoparticles (HA-MSNs) [73]

\section{Discussion}

Current screening methodology is efficient, however; a novel approach regarding therapy is needed. Several efforts have been made towards identifying the genome of CRC cancer and therefore providing targeted therapy, mostly in the form of chemotherapy or inhibitors. Gene therapy in the form of molecular pathway inhibition has been proposed with the help of drug delivery systems for efficient delivery such as; the SN-38, and nanoparticles [74-76], liposomes [77], carbon nanotubes [78] and polymeric micelles. $[79,80]$ Today the investigation of the various resistance mechanisms has led to the development of new drugs that can be specifically targeted as inhibitors of certain molecular pathways.[81] In the case however, of chemotherapy drugs these drugs suffer from a substantial failure rate and from toxicity.[82] Therefore although there is the trend to administer chemotherapy based on the molecular genome, additional efforts to overcome resistance to chemotherapy has been so far unsuccessful because of the ambiguous inter- and intratumor heterogeneity (tumor matrix) and complex biology of cancer cells with wide individual variations.[83] Enhancing treatment with gene targeting relies on the selection of a gene for treatment, therefore, the identification of a specific target affecting tumors is important. It has been observed that chromosome instability is a common feature of tumor cells, and is an important mechanism in tumor formation. [84-86]

Moreover; accurate regulation of the binding and dynamic changes of microtubules is essential for chromosome stability. Non-specific cytotoxic agents act on different phases of the cell division, if additional drug selection is done based on the overexpressed genes then non-specific cytotoxic agents become more efficient. Furthermore, drugs designed with polymers, microparticles, liposomes, solid lipid nanoparticles might be used for targeting of anticancer drug to colon tumor as they can penetrate the tumor microenvironment more efficiently. Diffusion of a dtug within a solid tumor is a very important factor for efficient therapy. Gene therapy is an optimistic approach in cancer treatment utilization the inhibition methodology. Probably in the future we will use gene therapy as immunotherapy for up-regulation of our immune system. Nowadays for efficient delivery of gene materials, designing an appropriate vector is necessary. Several carriers are being used such as; plasmids, antisense, and siRNA which become a promising approach in treatment of various forms of cancer such as colon cancer. It has been observed that nanoparticles can be administered either as both as 
oral and as injectable DNA delivery system. Moreover; no obvious toxicities of D-NPs have been observed, indicating that D-NPs are safe for systemic administration. D-NPs offer an innovative strategy for gene therapy delivery by intravenous injection and this delivery system might be a potential therapeutic approach for various cancers.[63] Future studies will elucidate probably a combination of injectable non-specific cytotoxic drugs with pill as gene inhibitors making CRC treatment more efficient.

\section{Competing Interests}

The authors have declared that no competing interest exists.

\section{References}

1. Torre LA, Bray F, Siegel RL, Ferlay J, Lortet-Tieulent J, Jemal A. Global cancer statistics, 2012. CA: a cancer journal for clinicians. 2015; 65: 87-108. doi:10.3322/caac.21262

2. Pham NM, Mizoue T, Tanaka K, Tsuji I, Tamakoshi A, Matsuo K, et al. Meat consumption and colorectal cancer risk: an evaluation based on a systematic review of epidemiologic evidence among the Japanese population. Japanese journal of clinical oncology. 2014; 44: 641-50. doi:10.1093/jjco/hyu061.

3. Wolin KY, Yan Y, Colditz GA, Lee IM. Physical activity and colon cancer prevention: a meta-analysis. British journal of cancer. 2009; 100: 611-6. doi:10.1038/sj.bjc.6604917.

4. Thune I, Furberg AS. Physical activity and cancer risk: dose-response and cancer, all sites and site-specific. Medicine and science in sports and exercise. 2001; 33: S530-50; discussion S609-10.

5. Moradi T, Gridley G, Bjork J, Dosemeci M, Ji BT, Berkel HJ, et al. Occupational physical activity and risk for cancer of the colon and rectum in Sweden among men and women by anatomic subsite. European journal of cancer prevention : the official journal of the European Cancer Prevention Organisation. 2008; 17: 201-8. doi:10.1097/CEJ.0b013e3282b6fd78.

6. van der Pool AE, Damhuis RA, Ijzermans JN, de Wilt JH, Eggermont AM, Kranse $R$, et al. Trends in incidence, treatment and survival of patients with stage IV colorectal cancer: a population-based series. Colorectal disease : the official journal of the Association of Coloproctology of Great Britain and Ireland. 2012; 14: 56-61. doi:10.1111/j.1463-1318.2010.02539.x

7. DeSantis CE, Lin CC, Mariotto AB, Siegel RL, Stein KD, Kramer JL, et al. Cancer treatment and survivorship statistics, 2014. CA: a cancer journal for clinicians. 2014; 64: 252-71. doi:10.3322/caac.21235.

8. Krell RW, Regenbogen SE, Wong SL. Variation in hospital treatment patterns for metastatic colorectal cancer. Cancer. 2015; 121: 1755-61. doi:10.1002/cncr.29253.

9. Binefa G, Rodriguez-Moranta F, Teule A, Medina-Hayas M. Colorectal cancer: from prevention to personalized medicine. World journal of gastroenterology. 2014; 20: 6786-808. doi:10.3748/wjg.v20.i22.6786.

10. Bian B, Mongrain S, Cagnol S, Langlois MJ, Boulanger J, Bernatchez G, et al. Cathepsin B promotes colorectal tumorigenesis, cell invasion, and metastasis. Molecular carcinogenesis. 2016; 55: 671-87. doi:10.1002/mc.22312.

11. Kahlenberg MS, Sullivan JM, Witmer DD, Petrelli NJ. Molecular prognostics in colorectal cancer. Surgical oncology. 2003; 12: 173-86.

12. Compton CC. Colorectal carcinoma: diagnostic, prognostic, and molecular features. Modern pathology : an official journal of the United States and Canadian Academy of Pathology, Inc. 2003; 16: 376-88. doi:10.1097/01.MP.0000062859.46942.93.

13. Berg M, Nordgaard O, Korner H, Oltedal S, Smaaland R, Soreide JA, et al. Molecular subtypes in stage II-III colon cancer defined by genomic instability: early recurrence-risk associated with a high copy-number variation and loss of RUNX3 and CDKN2A. PloS one. 2015; 10: e0122391. doi:10.1371/journal.pone.0122391.

14. Liu P, Carvalho CM, Hastings PJ, Lupski JR. Mechanisms for recurrent and complex human genomic rearrangements. Current opinion in genetics \& development. 2012; 22: 211-20. doi:10.1016/j.gde.2012.02.012.

15. Bonura F, Di Lisi D, Novo S, D'Alessandro N. Timely recognition of cardiovascular toxicity by anticancer agents: a common objective of the pharmacologist, oncologist and cardiologist. Cardiovascular toxicology. 2012; 12: 93-107. doi:10.1007/s12012-011-9141-z.

16. Pirri C, Bayliss E, Trotter J, Olver IN, Katris P, Drummond P, et al. Nausea still the poor relation in antiemetic therapy? The impact on cancer patients' quality of life and psychological adjustment of nausea, vomiting and appetite loss, individually and concurrently as part of a symptom cluster. Supportive care in cancer : official journal of the Multinational Association of Supportive Care in Cancer. 2013; 21: 735-48. doi:10.1007/s00520-012-1574-9.

17. Ruggiero A, Trombatore G, Triarico S, Arena R, Ferrara P, Scalzone M, et al. Platinum compounds in children with cancer: toxicity and clinical management. Anti-cancer drugs. 2013; 24: 1007-19. doi:10.1097/CAD.0b013e3283650bda.

18. Meyerhardt JA, Mayer RJ. Systemic therapy for colorectal cancer. The New England journal of medicine. 2005; 352: 476-87. doi:10.1056/NEJMra040958.

19. Loupakis F, Cremolini C, Masi G, Lonardi S, Zagonel V, Salvatore L, et al. Initial therapy with FOLFOXIRI and bevacizumab for metastatic colorectal cancer. The New England journal of medicine. 2014; 371: 1609-18. doi:10.1056/NEJMoa1403108.

20. Tol J, Koopman M, Cats A, Rodenburg CJ, Creemers GJ, Schrama JG, et al. Chemotherapy, bevacizumab, and cetuximab in metastatic colorectal cancer. The New England journal of medicine. 2009; 360: 563-72. doi:10.1056/NEJMoa0808268.

21. Colussi D, Brandi G, Bazzoli F, Ricciardiello L. Molecular pathways involved in colorectal cancer: implications for disease behavior and prevention. International journal of molecular sciences. 2013; 14: 16365-85. doi:10.3390/ijms140816365.

22. Zoratto F, Rossi L, Verrico M, Papa A, Basso E, Zullo A, et al. Focus on genetic and epigenetic events of colorectal cancer pathogenesis: implications for molecular diagnosis. Tumour biology : the journal of the International Society for Oncodevelopmental Biology and Medicine. 2014; 35: 6195-206. doi:10.1007/s13277-014-1845-9.

23. $\mathrm{Ng} \mathrm{JM}, \mathrm{Yu}$ J. Promoter hypermethylation of tumour suppressor genes as potential biomarkers in colorectal cancer. International journal of molecular sciences. 2015; 16: 2472-96. doi:10.3390/ijms16022472.

24. Fearon ER, Vogelstein B. A genetic model for colorectal tumorigenesis. Cell. 1990; 61: 759-67.

25. Andreyev HI, Norman AR, Cunningham D, Oates JR, Clarke PA. Kirsten ras mutations in patients with colorectal cancer: the multicenter "RASCAL" study. Journal of the National Cancer Institute. 1998; 90: 675-84

26. Samowitz WS, Curtin K, Schaffer D, Robertson M, Leppert M, Slattery ML. Relationship of Ki-ras mutations in colon cancers to tumor location, stage, and survival: a population-based study. Cancer epidemiology, biomarkers \& prevention : a publication of the American Association for Cancer Research, cosponsored by the American Society of Preventive Oncology. 2000; 9: 1193-7.

27. Walther A, Johnstone E, Swanton C, Midgley R, Tomlinson I, Kerr D. Genetic prognostic and predictive markers in colorectal cancer. Nature reviews Cancer. 2009; 9: 489-99. doi:10.1038/nrc2645.

28. Imamura Y, Lochhead P, Yamauchi M, Kuchiba A, Qian ZR, Liao X, et al. Analyses of clinicopathological, molecular, and prognostic associations of KRAS codon 61 and codon 146 mutations in colorectal cancer: cohort study and literature review. Molecular cancer. 2014; 13: 135. doi:10.1186/1476-4598-13-135.

29. Neumann J, Zeindl-Eberhart E, Kirchner T, Jung A. Frequency and type of KRAS mutations in routine diagnostic analysis of metastatic colorectal cancer. Pathology, research and practice. 2009; 205: 858-62. doi:10.1016/j.prp.2009.07.010.

30. Chen J, Huang XF, Qiao L, Katsifis A. Insulin caused drug resistance to oxaliplatin in colon cancer cell line HT29. Journal of gastrointestinal oncology. 2011; 2: 27-33. doi:10.3978/j.issn.2078-6891.2010.028.

31. Tripathi V, Bansal S, Alok S, Ravi B, Devra AK, Saxena S. Histopathological changes of radial artery wall in patients of chronic kidney disease stage 5 undergoing AV fistula formation and their correlation with serum iPTH levels. Saudi journal of kidney diseases and transplantation : an official publication of the Saudi Center for Organ Transplantation, Saudi Arabia. 2015; 26: 884-9. doi:10.4103/1319-2442.164562.

32. Reya T, Morrison SJ, Clarke MF, Weissman IL. Stem cells, cancer, and cancer stem cells. Nature. 2001; 414: 105-11. doi:10.1038/35102167.

33. Wang WJ, Wu MY, Shen M, Zhi Q, Liu ZY, Gong FR, et al. Cantharidin and norcantharidin impair stemness of pancreatic cancer cells by repressing the beta-catenin pathway and strengthen the cytotoxicity of gemcitabine and erlotinib. International journal of oncology. 2015; 47: 1912-22. doi:10.3892/ijo.2015.3156.

34. Liu W, Dong X, Mai M, Seelan RS, Taniguchi K, Krishnadath KK, et al. Mutations in AXIN2 cause colorectal cancer with defective mismatch 
repair by activating beta-catenin/TCF signalling. Nature genetics. 2000; 26: 146-7. doi:10.1038/79859.

35. Miyoshi Y, Nagase H, Ando H, Horii A, Ichii S, Nakatsuru S, et al. Somatic mutations of the APC gene in colorectal tumors: mutation cluster region in the APC gene. Human molecular genetics. 1992; 1: 229-33.

36. Morin PJ, Sparks AB, Korinek V, Barker N, Clevers H, Vogelstein B, et al. Activation of beta-catenin-Tcf signaling in colon cancer by mutations in beta-catenin or APC. Science. 1997; 275: 1787-90.

37. Clevers H. Wnt/beta-catenin signaling in development and disease. Cell. 2006; 127: 469-80. doi:10.1016/j.cell.2006.10.018.

38. Segditsas S, Tomlinson I. Colorectal cancer and genetic alterations in the Wnt pathway. Oncogene. 2006; 25: 7531-7. doi:10.1038/sj.onc.1210059.

39. Tian XH, Hou WJ, Fang Y, Fan J, Tong H, Bai SL, et al. XAV939, a tankyrase 1 inhibitior, promotes cell apoptosis in neuroblastoma cell lines by inhibiting Wnt/beta-catenin signaling pathway. Journal of experimental \& clinical cancer research : CR. 2013; 32: 100. doi:10.1186/1756-9966-32-100.

40. Wu X, Luo F, Li J, Zhong X, Liu K. Tankyrase 1 inhibitior XAV939 increases chemosensitivity in colon cancer cell lines via inhibition of the Wnt signaling pathway. International journal of oncology. 2016; 48 : 1333-40. doi:10.3892/ijo.2016.3360.

41. Huang XF, Chen JZ. Obesity, the PI3K/Akt signal pathway and colon cancer. Obesity reviews : an official journal of the International Association for the Study of Obesity. 2009; 10: 610-6. doi:10.1111/j.1467-789X.2009.00607.x.

42. Lind GE, Kleivi K, Meling GI, Teixeira MR, Thiis-Evensen E, Rognum TO, et al. ADAMTS1, CRABP1, and NR3C1 identified as epigenetically deregulated genes in colorectal tumorigenesis. Cellular oncology : the official journal of the International Society for Cellular Oncology. 2006; 28: 259-72.

43. Bal O, Yalcintas Arslan U, Durnali A, Uyetrk U, Demirci A, Tastekin D, et al. Progesterone receptor status in determining the prognosis of estrogen receptor positive/ HER2 negative breast carcinoma patients. Journal of BUON : official journal of the Balkan Union of Oncology. 2015; 20: $28-34$

44. Bardou VJ, Arpino G, Elledge RM, Osborne CK, Clark GM. Progesterone receptor status significantly improves outcome prediction over estrogen receptor status alone for adjuvant endocrine therapy in two large breast cancer databases. Journal of clinical oncology : official journal of the American Society of Clinical Oncology. 2003; 21: 1973-9. doi:10.1200/JCO.2003.09.099.

45. Liu M, Tang Q, Qiu M, Lang N, Li M, Zheng Y, et al. miR-21 targets the tumor suppressor RhoB and regulates proliferation, invasion and apoptosis in colorectal cancer cells. FEBS letters. 2011; 585: 2998-3005. doi:10.1016/j.febslet.2011.08.014.

46. Liu F, Liu Y, Shen J, Zhang G, Han J. MicroRNA-224 inhibits proliferation and migration of breast cancer cells by down-regulating Fizzled 5 expression. Oncotarget. 2016; 7: 49130-42. doi:10.18632/oncotarget.9734.

47. Rayburn ER, Wang W, Zhang R, Wang H. Experimental therapy for colon cancer: anti-cancer effects of TLR9 agonism, combination with other therapeutic modalities, and dependence upon p53. International journal of oncology. 2007; 30: 1511-9.

48. Zuckerman DS, Clark JW. Systemic therapy for metastatic colorectal cancer: current questions. Cancer. 2008; 112: 1879-91. doi:10.1002/cncr.23409.

49. Tomar RS, Matta H, Chaudhary PM. Use of adeno-associated viral vector for delivery of small interfering RNA. Oncogene. 2003; 22: 5712-5. doi:10.1038/sj.onc.1206733.

50. Singh Y, Gao D, Gu Z, Li S, Rivera KA, Stein S, et al. Influence of molecular size on the retention of polymeric nanocarrier diagnostic agents in breast ducts. Pharmaceutical research. 2012; 29: 2377-88. doi:10.1007/s11095-012-0763-z.

51. Chen Y, Huang L. Tumor-targeted delivery of siRNA by non-viral vector: safe and effective cancer therapy. Expert opinion on drug delivery. 2008; 5: 1301-11. doi:10.1517/17425240802568505.

52. Kim SH, Jeong JH, Lee SH, Kim SW, Park TG. PEG conjugated VEGF siRNA for anti-angiogenic gene therapy. Journal of controlled release : official journal of the Controlled Release Society. 2006; 116: 123-9. doi:10.1016/j.jconrel.2006.05.023.

53. Lee SY, Yang CY, Peng CL, Wei MF, Chen $K C$, Yao CJ, et al. A theranostic micelleplex co-delivering SN-38 and VEGF siRNA for colorectal cancer therapy. Biomaterials. 2016; 86: 92-105. doi:10.1016/j.biomaterials.2016.01.068.

54. Hussain A, Qazi AK, Mupparapu N, Guru SK, Kumar A, Sharma PR, et al. Modulation of glycolysis and lipogenesis by novel PI3K selective molecule represses tumor angiogenesis and decreases colorectal cancer growth. Cancer letters. 2016; 374: 250-60. doi:10.1016/j.canlet.2016.02.030.

55. Davudian S, Shajari N, Kazemi T, Mansoori B, Salehi S, Mohammadi A, et al. BACH1 silencing by siRNA inhibits migration of HT-29 colon cancer cells through reduction of metastasis-related genes. Biomedicine $\&$ pharmacotherapy = Biomedecine \& pharmacotherapie. 2016; 84: 191-8. doi:10.1016/j.biopha.2016.09.021.

56. Kiani M, Mirzazadeh Tekie FS, Dinarvand M, Soleimani M, Dinarvand $\mathrm{R}$, Atyabi F. Thiolated carboxymethyl dextran as a nanocarrier for colon delivery of hSET1 antisense: In vitro stability and efficiency study. Materials science \& engineering C, Materials for biological applications. 2016; 62: 771-8. doi:10.1016/j.msec.2016.02.009.

57. Liang X, Luo M, Wei XW, Ma CC, Yang YH, Shao B, et al. A folate receptor-targeted lipoplex delivering interleukin-15 gene for colon cancer immunotherapy. Oncotarget. 2016; 7: 52207-17. doi:10.18632/oncotarget.10537.

58. Ayeka PA, Bian Y, Mwitari PG, Chu X, Zhang Y, Uzayisenga R, et al. Immunomodulatory and anticancer potential of Gan cao (Glycyrrhiza uralensis Fisch.) polysaccharides by CT-26 colon carcinoma cell growth inhibition and cytokine IL-7 upregulation in vitro. BMC complementary and alternative medicine. 2016; 16: 206. doi:10.1186/s12906-016-1171-4.

59. Zhang B, Li A, Zuo F, Yu R, Zeng Z, Ma H, et al. Recombinant Lactococcus lactis NZ9000 secretes a bioactive kisspeptin that inhibits proliferation and migration of human colon carcinoma HT-29 cells. Microbial cell factories. 2016; 15: 102. doi:10.1186/s12934-016-0506-7.

60. Song L, Fan Z, Jun N, Benjia L, Zequn L, Xilong W, et al. Tumor specific delivery and therapy mediate by integrin beta6-target immunoliposomes for beta6-siRNA in colon carcinoma. Oncotarget. 2016. doi:10.18632/oncotarget.13209.

61. Ye P, Xing H, Lou F, Wang K, Pan Q, Zhou X, et al. Histone deacetylase 2 regulates doxorubicin (Dox) sensitivity of colorectal cancer cells by targeting ABCB1 transcription. Cancer chemotherapy and pharmacology. 2016; 77: 613-21. doi:10.1007/s00280-016-2979-9.

62. Oh BY, Kim KH, Chung SS, Lee RA. Silencing the livin gene enhances the cytotoxic effects of anticancer drugs on colon cancer cells. Annals of surgical treatment and research. 2016; 91: 273-7. doi:10.4174/astr.2016.91.6.273.

63. Yu T, Xu B, He L, Xia S, Chen Y, Zeng J, et al. Pigment epithelial-derived factor gene loaded novel COOH-PEG-PLGA-COOH nanoparticles promoted tumor suppression by systemic administration. International journal of nanomedicine. 2016; 11: 743-59. doi:10.2147/IJN.S97223.

64. Zhou D, Zhang YI, Liang D, Yuan Y, Zeng D, Chen J, et al. Effect of combination therapy of siRNA targeting growth hormone receptor and 5 -fluorouracil in hepatic metastasis of colon cancer. Oncology letters. 2015; 10: 3505-9. doi:10.3892/ol.2015.3770.

65. Li K, Zhou ZY, Ji PP, Luo HS. Knockdown of beta-catenin by siRNA influences proliferation, apoptosis and invasion of the colon cancer cell line SW480. Oncology letters. 2016; 11: 3896-900. doi:10.3892/ol.2016.4481.

66. Zhao C, Wang W, Yu W, Jou D, Wang Y, Ma H, et al. A novel small molecule STAT3 inhibitor, LY5, inhibits cell viability, colony formation, and migration of colon and liver cancer cells. Oncotarget. 2016; 7: 12917-26. doi:10.18632/oncotarget.7338.

67. Wang Y, Wang M, Li Y. Anti-colorectal cancer effect of interleukin-2 and interferon-beta fusion gene driven by carcinoembryonic antigen promoter. OncoTargets and therapy. 2016; 9: 3259-67. doi:10.2147/OTT.S97444.

68. Zhu P, Zhao N, Sheng D, Hou J, Hao C, Yang X, et al. Inhibition of Growth and Metastasis of Colon Cancer by Delivering 5-Fluorouracil-loaded Pluronic P85 Copolymer Micelles. Scientific reports. 2016; 6: 20896. doi:10.1038/srep20896.

69. Cho YS, Do MH, Kwon SY, Moon C, Kim K, Lee K, et al. Efficacy of CD46-targeting chimeric Ad5/35 adenoviral gene therapy for colorectal cancers. Oncotarget. 2016; 7: 38210-23. doi:10.18632/oncotarget.9427.

70. Cho YS, Yoon TJ, Jang ES, Soo Hong K, Young Lee S, Ran Kim O, et al. Cetuximab-conjugated magneto-fluorescent silica nanoparticles for in vivo colon cancer targeting and imaging. Cancer letters. 2010; 299: 63-71. doi:10.1016/j.canlet.2010.08.004.

71. Glavas-Dodov M, Steffansen B, Crcarevska MS, Geskovski N, Dimchevska S, Kuzmanovska $S$, et al. Wheat germ agglutinin-functionalised crosslinked polyelectrolyte microparticles for local colon delivery of 5-FU: in vitro efficacy and in vivo gastrointestinal distribution. Journal of microencapsulation. 2013; 30: 643-56. doi:10.3109/02652048.2013.770099.

72. Hsieh WJ, Liang CJ, Chieh JJ, Wang SH, Lai IR, Chen JH, et al. In vivo tumor targeting and imaging with anti-vascular endothelial growth factor antibody-conjugated dextran-coated iron oxide nanoparticles. International journal of nanomedicine. 2012; 7 : 2833-42. doi:10.2147/IJN.S32154. 
73. Yu M, Jambhrunkar S, Thorn P, Chen J, Gu W, Yu C. Hyaluronic acid modified mesoporous silica nanoparticles for targeted drug delivery to CD44-overexpressing cancer cells. Nanoscale. 2013; 5: 178-83. doi:10.1039/c2nr32145a.

74. Sayari E, Dinarvand M, Amini M, Azhdarzadeh M, Mollarazi E, Ghasemi Z, et al. MUC1 aptamer conjugated to chitosan nanoparticles, an efficient targeted carrier designed for anticancer SN38 delivery. International journal of pharmaceutics. 2014; 473: 304-15. doi:10.1016/j.ijpharm.2014.05.041.

75. Peng CL, Tsai HM, Yang SJ, Luo TY, Lin CF, Lin WJ, et al. Development of thermosensitive poly(n-isopropylacrylamide-co-((2-dimethylamino) ethyl methacrylate))-based nanoparticles for controlled drug release. Nanotechnology. 2011; 22: 265608. doi:10.1088/0957-4484/22/26/265608.

76. Sharma M, Malik R, Verma A, Dwivedi P, Banoth GS, Pandey N, et al. Folic acid conjugated guar gum nanoparticles for targeting methotrexate to colon cancer. Journal of biomedical nanotechnology. 2013; 9: 96-106.

77. Pal A, Khan S, Wang YF, Kamath N, Sarkar AK, Ahmad A, et al. Preclinical safety, pharmacokinetics and antitumor efficacy profile of liposome-entrapped SN-38 formulation. Anticancer research. 2005; 25: 331-41.

78. Lee PC, Chiou YC, Wong JM, Peng CL, Shieh MJ. Targeting colorectal cancer cells with single-walled carbon nanotubes conjugated to anticancer agent SN-38 and EGFR antibody. Biomaterials. 2013; 34: 8756-65. doi:10.1016/j.biomaterials.2013.07.067.

79. Matsumura Y. Preclinical and clinical studies of NK012, an SN-38-incorporating polymeric micelles, which is designed based on
EPR effect. Advanced drug delivery reviews. 2011; 63: 184-92. doi:10.1016/j.addr.2010.05.008.

80. Peng CL, Lai PS, Lin FH, Yueh-Hsiu Wu S, Shieh MJ. Dual chemotherapy and photodynamic therapy in an HT-29 human colon cancer xenograft model using SN-38-loaded chlorin-core star block copolymer micelles. Biomaterials. 2009; 30: 3614-25. doi:10.1016/j.biomaterials.2009.03.048

81. Mellor HR, Callaghan R. Resistance to chemotherapy in cancer: a complex and integrated cellular response. Pharmacology. 2008; 81: 275-300. doi:10.1159/000115967.

82. Widakowich C, de Castro G, Jr., de Azambuja E, Dinh P, Awada A. Review: side effects of approved molecular targeted therapies in solid $\begin{array}{llll}\text { cancers. The } \quad \text { oncologist. 2007; 12: } & \end{array}$ doi:10.1634/theoncologist.12-12-1443.

83. Lippert TH, Ruoff HJ, Volm M. Intrinsic and acquired drug resistance in malignant tumors. The main reason for therapeutic failure. Arzneimittel-Forschung. 2008; 58: 261-4. doi:10.1055/s-0031-1296504.

84. Luo F, Poulogiannis G, Ye H, Hamoudi R, Zhang W, Dong G, et al. Mutant K-ras promotes carcinogen-induced murine colorectal tumourigenesis, but does not alter tumour chromosome stability. The Journal of pathology. 2011; 223: 390-9. doi:10.1002/path.2790.

85. Venkitaraman AR. Chromosome stability, DNA recombination and the BRCA2 tumour suppressor. Current opinion in cell biology. 2001; 13: 338-43.

86. Venkitaraman AR. Tumour suppressor mechanisms in the control of chromosome stability: insights from BRCA2. Molecules and cells. 2014; 37: 95-9. doi:10.14348/molcells.2014.2346. 